\title{
Prediction of Infarct Coronary Artery Recanalization After Intravenous Thrombolytic Therapy
}

\author{
BARBARA J. KIRCHER, MD, ERIC J. TOPOL, MD, WILLIAM W. O'NEILL, MD, \\ and BERTRAM PITT, MD
}

\begin{abstract}
Clinical assessment of patlents with evolving acute myocardial infarction may suggest recanalization of the infarct coronary artery if chest pain, electrocardiographic ST-segment elevation and reperfusion arihythmia are diminished. These 3 criteria, however, have not been correlated with immediate coronary angiography. Determination of which patients will achieve myocardial reperfusion after intravenous fibrinolytic therapy would allow for appropriate triage; those in whom it fails may be considered for mechanical or surgical recanalization. Fifty-six patients were studied: 28 recelved intravenous streptokinase and 28 intravenous recombinant tissue-type plas-
\end{abstract}

minogen activator. None of these clinical criterla, considered separately, was predictive of infarct artery recanalization status. Using the presence or absence of all 3 criteria, the specificity and predictive value increased to $100 \%$. However, only $9 \%$ of patients in the series had all 3 criteria present (all had a patent infarct artery) and $34 \%$ had no criteria present (all had an occluded vessel). Noninvasive clinical markers are simple and practical, but only concordance of all 3 major criteria, when present, accurately predicts results of thrombolytic therapy.

(Am J Cardiol 1987;59:513-515)
E arly intravenous fibrinolytic therapy in acute myocardial infarction (AMI) has been shown to reduce mortality risk. ${ }^{1,2}$ Using the thrombolytic agents available or under investigation, a 50 to $75 \%$ infarct-vessel recanalization rate can be expected..$^{3-7}$ The 25 to $50 \%$ of patients in whom thrombolytic therapy fails remain candidates for urgent mechanical recanalization of the occluded artery with percutaneous transluminal coronary angiplasty. This alternative therapy has been shown to promote myocardial functional recovery. ${ }^{8,9}$

If one could quickly and reliably predict which patients will respond favorably to intravenous thrombolysis, the need for emergency cardiac catheterization and PTCA might be obviated in some patients. Three clinical criteria have been proposed as markers for myocardial reperfusion: reduction of chest discomfort, improvement of electrocardiographic ST-segment elevation and reperfusion arrhythmias. ${ }^{10}$ Despite their common usage in assessing patients who receive

From the Division of Cardiology, Department of Internal Medicine, University of Michigan Medical Center, 1500 East Medical Center Drive, Ann Arbor, Michigan. Manuscript received August 19, 1986; revised manuscript received October 9, 1986; accepted October 10, 1986.

Address for reprints: Eric J. Topol, MD, UH B1 F245, 1500 East Medical Center Drive, University of Michigan Medical Center, Ann Arbor, Michigan 48109. thrombolytic therapy, these criteria have not been evaluated in relation to immediate arteriographic findings. The present study is the first prospective demonstration of the predictive value of these criteria for infarct-vessel recanalization after intravenous thrombolytic therapy.

\section{Methods}

Fifty-six consecutive patients who received intravenous thrombolytic therapy for transmural AMI, with less than 6 hours of chest pain, were studied. All patients had at least $2 \mathrm{~mm}$ of ST-segment elevation in 2 or more contiguous electrocardiographic leads before initiation of treatment. Intravenous streptokinase, at a dose of 1.5 million units over 30 minutes, was given to 28 patients and intravenous human tissue-type plasminogen activator, at $1.25 \mathrm{mg} / \mathrm{kg}$ over 3 hours, was administered to 28 . The following data were prospectively collected before and 90 minutes after thrombolytic therapy: (1) change in chest discomfort intensity on a subjective scale from 0 to 10 , with a decrease of at least 2 representing improvement; (2) electrocardiographic ST-segment elevation averaged in the 2 contiguous leads showing maximal elevation in a 12-lead tracing; and (3) reperfusion arrhythmia, defined as an arrhythmia noted during the 90-minute period of administering thrombolytic therapy. The following arrhythmias were considered suggestive of reperfusion: 
TABLE I Predictive Value of Clinical Criteria for Recanalization Status

\begin{tabular}{lccccc}
\hline & No. of Pts & $(\%)$ & Sens (\%) & Spec (\%) & PV (\%) \\
\hline Chest pain $\downarrow$ & 25 & $(44 \%)$ & 81 & 73 & 84 \\
ST segment $\downarrow$ & 18 & $(33 \%)$ & 52 & 88 & 88 \\
Arrhythmia & 17 & $(30 \%)$ & 37 & 84 & 82 \\
CP $\downarrow+$ ST $\downarrow$ & 10 & $(18 \%)$ & 32 & 95 & 90 \\
CP $\downarrow+$ ST $\downarrow+$ A & 5 & $(9 \%)$ & 14 & 100 & 100 \\
\hline
\end{tabular}

$A=$ arrhythmia; $C P=$ chest pain; $P V=$ predictive value; Sens $=$ sensitivity; $S p e c=$ specificity $\downarrow \downarrow$ = decrease.

accelerated idioventricular or junctional rhythm, paroxysmal sinus bradycardia (less than 50 beats $/ \mathrm{min}$ ) second- or third-degree atrioventricular block, ventricular tachycardia (at least $3 \cdot$ beats) and ventricular fibrillation.

At 90 minutes after the initiation of thrombolytic therapy, patients underwent selective coronary arteriography through the transfemoral approach. All patients received $5,000 \mathrm{U}$ of heparin after arterial access was obtained. No intracoronary nitroglycerin was administered before the first infarct-vessel angiogram. This angiogram was used to grade infarct-vessel patency according to criteria from the Thrombolysis in Myocardial Infarction trial (grade 2 or $3=$ patency), ${ }^{11}$ independent of the clinical data.

To determine the predictive value for each of the clinical criteria and combinations of these criteria, sensitivity, specificity and predictive value was calculated as follows:

Sensitivity $=$ number of patients with patent artery and reperfusion criteria present/number of patients with patent vessel.

Specificity $=$ number of patients with occluded artery and without reperfusion criteria present/number of patients with occluded vessel.

Predictive value $=$ number of patients with patent artery and reperfusion criteria/number of patients with reperfusion criteria.

\section{Results}

Of the 56 patients studied, 44 were men and 12 women, mean age $56 \pm 9$ years. The time from onset of chest pain to thrombolytic therapy was $3.1 \pm 0.9$ hours and from chest pain to cardiac catheterization $4.2 \pm 1.2$ hours. The infarct-related artery was the left anterior descending in 24 patients, the left circumflex in 7 and the right coronary artery in 25 . Recanalization occurred in 37 of the 56 patients $(66 \%)$ in this series.

Table I lists the percentage of patients in whom each of the 3 major reperfusion criteria were present compared with recanalization status, expressed as sensitivity, specificity and predictive value. The sensitivity and specificity were not adequate for ST segment and arrhythmia considered separately (Table I). The sensitivity and predictive value of chest pain improvement was $81 \%$ and $84 \%$, respectively. By combining a decrease in chest discomfort and ST-segment improvement, a higher specificity and predictive value were achieved. Using all 3 criteria, a predictive value of $100 \%$ was found. However, this resulted in only 5 of 37 patients ( $14 \%$ sensitivity) who had confirmed angiographic patency having all 3 criteria present. In contrast, of the 19 patients who had no criteria present, all had infarct-vessel occlusion. There were no differences in predictive value for inferior vs anterior infarction, time from administration of the drug from chest pain onset or plasminogen activator vs streptokinase.

\section{Discussion}

The results of the present study suggest that the clinical markers for predicting infarct-vessel recanalization after thrombolytic therapy are inadequate. Each criteria considered separately was relatively insensitive and lacked specificity. By combining criteria-if all 3 were absent or present-the predictive value was acceptable. However, all 3 criteria were present in only 5 of 37 patients $(14 \%)$ who had angiographic evidence of coronary recanalization and all 3 criteria were absent in 15 of 19 patients with persistent occlusion. These findings are different from those of Lew et al. ${ }^{12}$ Acute coronary arteriography was performed in all our patients rather than at 3 to 4 days, as in the study of Lew et al. ${ }^{12}$ Perhaps more important, we used the coronary arteriogram rather than early peaking of creatine kinase curves to demonstrate reperfusion.

Multiple confounding variables make the clinical criteria for reperfusion unreliable. Patients often require opiate narcotics for treatment of chest pain, and these drugs may interfere with our ability to judge whether relief or improvement has occurred..$^{13}$ Similarly, as myonecrosis ensues, there will be relief of pain. A decrease in ST-segment elevation may be difficult to evaluate because it typically occurs as part of evolutionary electrocardiographic changes. Finally, reperfusion arrhythmias can occur spontaneously in the early hours of infarction without reperfusion. Before the routine use of thrombolytic therapy, such rhythm disturbances were considered part of the natural history of myocardial infarction. ${ }^{14}$

There remains a critical need for a noninvasive marker of myocardial reperfusion. Such a marker could allow patients to be appropriately triaged to the coronary care unit for adjunctive therapy directed to sustaining coronary arterial patency, or to a cardiac catheterization laboratory for angiography and consideration for PTCA. If proved effective, the latter strategy has important public health implications affecting the need for regionalization of interventional cardiac care and reliance on rapid interhospital transport such 
as the helicopter. ${ }^{15}$ In particular, patients at high risk, such as those with a large anterior myocardial infarct or pulmonary edema, may benefit from aggressive intervention with PTCA if intravenous thrombolysis has failed.

Several markers have been proposed to detect reperfusion. However, the test for creatine kinase isoenzyme levels ${ }^{16}$ and serum myoglobin may be fraught with practical and theoretical obstacles. First, such blood tests require a turnaround time that may only provide useful information after myonecrosis is already complete. Second, there appears to be a dynamic course of infarct-artery occlusion in many patients. Angiographically, intermittent patency and occlusion is not unusual. This problem could confound evaluation of an enzymatic test directed at appropriately triaging a patient. Holter ST-segment monitoring has been used to correlate with reperfusion, but the time needed to establish the trend and analyze the data, along with the relative lack of specificity, appear to make this particular technique impractical and inaccurate. ${ }^{17}$ Scintigraphic detection of intracoronary thrombus with paired indium-111 platelets and technetium-99m-labeled red blood cells has been shown. ${ }^{18}$ However, such a technique is not routinely available and lacks sensitivity for coronary patency vs presence of intraluminal thrombus. In comparison, noninvasive clinical markers of reperfusion are simple and practical, but only concordance of the 3 major criteria, when present, accurately predicts success or failure of thrombolytic therapy.

\section{References}

1. Gruppo Italiano Per Lo Studio Della Streptochinasi Nell'Infarcto Miocardio (GISSI). Effectiveness of intravenous thrombolytic treatment in acute myocardial infarction. Lancet 1986;1:397-401.

2. Yusuf S, Collins R, Peto R, Furberg C, Stampfer MJ, Goldhaber SZ, Hennekens $\mathrm{CH}$. Intravenous and intracoronary fibrinolytic therapy in acute myocardial infarction: overview of results on mortality, reinfarction and sideeffects from 33 rundomized controlled trials. Eur Heart J 1985;6:556-585. 3. Rentrop KP. Thrombolytic therapy in patients with acute myocardial infarction. Circulation 1985;71:627-631.
4. Verstraete M, Bory M, Collen D, Erbel R, Lennane RJ, Mathey D, Michels HR, Schartl M, Uebis R, Bernard R, Brower RW, de Boneo DP, Huhmann W, Lubsen ], Meyer ], Rutsch W, Schmidt W, von Essen R. Randomized trial of intravenous recombinant tissue type plasminogen activator versus intrave nous streptokinase in acute myocardial infarction. Lancet 1985;1:842-847. 5. Marder VI, Rothbard RL, Fitzpatrick PG, Francis CW. Rapid lysis of coronary artery thrombi with anisoylatcd plasminogen: streptakinase activator complex. Ann Intern Med 1986;104:304-310.

6. Collen D, Topol EJ, Tiefenbrunn AJ, Gold HK, Weisfeldt ML, Sobel BE, Leinbach RC, Brinker JA, Ludbrook PA, Yasuda I, Bulkley BH, Robison AK, Hutter AM, Bell WR, Spadaro JI, Khaw BA, Grossbard EB. Coronary thrombolysis with recombinant human tissue-type plasminogen activator: a prospective, randomized, placebo-controlled trial. Circulation 1984;70:10121017.

7. Topol EJ, O'Neill WW, Walton JA, Bourdillon PDV, Bates ER, Langburd A, Baumann G, Burney RE, Kline E, Schork MA, Pitt B. Preliminary report of a randomized, placebo controlled trial of recombinant tissue plasminogen activator and emergency coronary angioplasty in acute myocardial infarction. Clin Res 1986;34:349A.

8. O'Neill W, Timmis G, Bourdillon P, Lai P, Ganghadarhan V, Walton I, Ramos R, Laufer N, Gordon S, Schork MA, Pitt B. A prospective randomized clinical trial of intracoronary streptokinase versus coronary angioplasty therapy of acute myocardial infarction. N Engl I Med 1986;314:812-828.

9. Fung AY, Lai P, Topol EJ, Bates ER, Bourdillon PDV, Walton JA Jr, Mancini GBJ, Kryski T, Pitt B, O'Neill WW. Myocardial salvage by coronary angioplasty following thrombolytic failure in acute myocardial infarction. Am I Cardiol 1986; 59:in press.

10. Ganz W, Geft I, Shah PK, Lew AS, Rodriguez L, Weiss T, Maddahi J, Berman DS, Charuzi Y, Swan HJC. Intravenous streptokinase in evolving acute myocardial infarction. Am J Cardiol 1984;53:1209-1216.

11. TIMI Study Group. The Thrombolysis in Myocardinl Infarction (TIMI) trial. N Engl I Med 1985;312:932-936.

12. Lew AS, Laramee P, Cercek B, Rodriguez L, Shah PK, Ganz W. The effects of the rate of intravenous infusion of streptokinase and the duration of symptoms on the time interval to reperfusion in patients with acute myocardial infarction. Circulation 1985;72:1053-1058.

13. Herlitz J, Richter A, Hjalmarson A, Holmberg S. Variability of chest pain in suspected acute myocardial infarction according to subjective assessment and requirement of narcotic analgesics. Int / Cardiol 1986;13:9-11.

14. Kimball JT, Killip T. Aggressive treatment of arrhythmias in acute myocardial infarction. Prog Cardiovasc Dis 1968;10:483-498.

15. Topol E], Fung AY, Kline E, Kaplan L, Landis D, Strozeski M, Burney RE, Pitt B. O'Neill WW. Safety of helicopter transport and out-of-hospital intravenous fibrinolytic therapy in patients with evolving myocardial infarction. Cathet Cardiovasc Diagn 1986:12:151-155.

16. Devries SR, Sobel BE, Abendschein DR. Prompt detection of myocardial reperfusion by analysis of creatine kinase isoforms in plasma (abstr). JACC 1986;7:206A.

17. Krucoff MW, Green CE, Satler LF, Miller FC, Pallas RS, Kent KM, Del Negro AA, Pearle DL, Fletcher RD, Rackley CE. Noninvasive detection of coronary artery patency using continuous ST-segment monitoring. Am / Cardiol 1986;57:916-922.

18. Fox KAA, Bergmann SR, Mathias CJ, Powers WJ, Siegel BA, Welch MJ, Sobel BE. Scintigraphic detection of coronary artery thrombi in patients with acute myocardial infarction. JACC 1984;4:975-986. 